\title{
Fatty Acid Concentrations in Synchronous Cultures of Chlorella pyrenoidosa, Grown in the Presence and Absence of Glucose
}

\author{
RONALD C. REITZ ${ }^{1}$ and JAMES G. HAMILTON, Department of Biochemistry and the Nutrition \\ and Metabolism Laboratory of the Department of Medicine, Tulane University \\ School of Medicine, New Orleans, Louisiana, and FRANCIS E. COLE, Department of Biochemistry, \\ Louisiana State University School of Medicine, New Orleans, Louisiana
}

\section{ABSTRACT}

Total cellular fatty acids, of a hightemperature strain of Chlorella pyrenoidosa, were measured during a synchronous growth cycle in continuous light in the presence and absence of glucose.

The fatty acid composition, consisting of saturated monoenoic, dienoic, and trienoic $\mathrm{C}_{16}$ and $\mathrm{C}_{78}$ fatty acids, remained essentially the same whether or not the cells were grown on glucose.

Nearly all of the fatty acids increased irregularly in concentration during the growth cycle, showing a periodism during the prenuclear and cell-division stages of growth. Cultures exposed to glucose showed a more pronounced drop in the concentration of most of the fatty acids during both stages.

None of the fatty acid concentrations, some of which have been implicated in the Hill reaction of a number of photosynthetic organisms, reflected the periodism in photosynthetic activity which was previously observed during the synchronous growth cycle of this organism.

The changes in fatty acid concentration are discussed with relation to concurrent metabolic and cytological changes during cell maturation in this organism.

\section{INTRODUCTION}

$\mathrm{T}$ HE FATTY ACID COMPOSITION of algae has been investigated under a variety of nutritional and physiological conditions $(1,2)$. These data however have been obtained from cell cultures which contain cells of all ages. Though the general fatty acid pattern was established, little, if any, information has been

\footnotetext{
1 This paper represents part of a dissertation submitted by the senior author to the graduate school of Tulane University in partial fulfilment of requirements for the Ph.D. degree. Current address: Department of Biochemistry, University of Michigan School of Medicine, Ann Arbor, Mich.
}

gathered relating changes in either the pattern or the concentrations of these lipids to the process of cell maturation.

Problems concerning the growth and maturation of cells have been successfully approached by using cell populations the member cells of which all have been induced to grow and divide more or less simultaneously $(3,4)$. In such "synchronized cultures" visual cytological changes (5) (mitosis, cross-wall deposition, cytokinesis) occur more or less in phase and can be related to the metabolic changes (measured chemically) which accompany them (3).

Chlorella pyrenoidosa, a unicellular alga, can be induced to grow synchronously in mass cultures; at the same time it exhibits relatively normal logarithmic growth in other respects (6-8).

The cellular demands for energy- and carbon-building blocks during the nuclear division and cross-wall deposition stages of growth, coupled with an increase in the cellular respiration rate (9) and a decline in the photosynthetic activity (10) during the same period in synchronized Chlorella cultures, have led Duynstee and Schmidt (11) to infer that carbohydrate and/or lipid reserves which accumulate prior to this growth period might be mobilized at the time to meet the metabolic demands of these processes.

The $\alpha$-linolenic acid (12) as well as trans 3-hexadecenoic acid (13) have been suggested as being involved in the Hill reaction in various photosynthetic organisms. The absence of both of these fatty acids in two species of blue-green algae, which were nevertheless capable of performing the Hill reaction, has led Nichols (14) to conclude that the essential participation of either $\alpha$-linolenic acid or trans 3 -hexadecenoic acid in the Hill reaction can be discounted. The lack of universality in the distribution of these fatty acids does not however automatically preclude the possibility of their intimate involvement in the photosynthetic processes of green algae and higher plants. Synchronized cultures of the green 
algae Chlorella pyrenoidosa might afford a convenient test of this involvement by virtue of a dramatic periodism in the photosynthetic activity (10) during its growth cycle. Fatty acids associated with the photosynthetic process might be expected to exhibit a related periodism in their concentrations during a synchronous growth cycle of this organism.

The purpose of the present investigation was to determine whether possible periodism in the cellular levels of the fatty acids would implicate their involvement in the photosynthetic process and in the process of supplying carbon-building blocks and/or energy reserves at select intervals during the growth cycle of $C$. pyrenoidosa.

\section{MATERIALS AND METHODS}

\section{Organism}

The alga used in these studies was the hightemperature strain 7-11-05 of $C$. pyrenoidosa, described by Sorokin (15). The cells were synchronized by using the intermittent illumination method described by Schmidt (6) .

\section{Culture Conditions}

The cells were grown in $2 \times 21$-in. bubbler tubes immersed in a constant temperature $(38.5 \mathrm{C})$ water bath and illuminated by two banks of 40-watt fluorescent lights (eight each), which were mounted 3 in. from the outside edge of the tubes. The liquid medium, described by Sorokin (15) and modified by Johnson (16), was aerated with a $\mathrm{CO}_{2}$-air mixture $(3 \%)$. The entire growth chamber was housed in a light-tight cabinet.

Synchronized cultures grown for one growth cycle in continuous light under the above conditions exhibited a linear logarithmic increase in dry weight and phosphorus identical to that reported in other laboratories for this organism (6) (see Results).

The fatty acid content of the cells was measured at intervals during a synchronous growth cycle of $C$. pyrenoidosa in the presence of light: a) normal mineral medium (light, nonglucose)-(photo-autotrophic); b) normal mineral medium plus $0.2 \%$ glucose (light, glucose)-(photoheterotrophic). The conditions of temperature and aeration were identical for both experiments. Where indicated, sufficient sterile glucose, autoclaved separately from the mineral medium, was added to give a final concentration of $0.2 \% \mathrm{w} / \mathrm{v}$.

\section{Biochemical Measurements}

Cellular dry weight (17) and total cellular phosphorus (18) were determined in triplicate.
Cell number per $\mathrm{ml}$ was determined by using a Levy-Hauser hemocytometer.

The samples for triplicate lipid analysis were harvested directly from the culture tubes and placed into a Servall refrigerated centrifuge. The cells were centrifuged at $27,000 \times g$ for $7 \mathrm{~min}$. and washed three times with an icecold solution of $0.125 \%(\mathrm{w} / \mathrm{v})$, Tris (Tris hydroxyamino methane) $0.01 \% \mathrm{CaCl}_{2}(\mathrm{w} / \mathrm{v})$, $\mathrm{pH} 7.0$, to remove residual media materials. After the final wash about $5 \mathrm{ml}$ of cold distilled water were used quantitatively to transfer the cell material into Teflon-lined screw-cap test tubes. Five $\mathrm{ml}$ of cold absolute ethanol were added, and the sealed tubes were stored in a darkened refrigerator overnight.

Each sample was then sonicated by using the micro-tip attachment of a Branson Sonifier (Model 125), which was operated at a maximum power for $5 \mathrm{~min}$. The sonifier probe was immersed deeply into each sample tube, and the tube was cooled in a circulating acetone-ice bath at $-18 \mathrm{C}$. During the five minutes of sonication the contents of the tube remained below $5 \mathrm{C}$.

A known amount of myristic acid, a fatty acid which had been shown to be present in only trace quantities during a previous synchronous growth cycle, was added as an internal standard. Enough aqueous KOH (100 $\mathrm{g} / 100 \mathrm{ml}$ ) to make the final solution $10 \%$ $\mathrm{KOH}$ was added. The tubes were tightly sealed and placed in a water bath at $60 \mathrm{C}$ for one hour. The sealed tubes were allowed to stand overnight in the dark at room temperature, and the tube contents were again heated for one hour in a water bath, but this time at 70C. Upon cooling, the cell material was extracted three times with $\mathrm{n}$-hexane to remove the nonsaponifiable material. The mixture was then acidified with $25 \% \mathrm{HCl}$ and extracted three more times with n-hexane. This extract was washed free of $\mathrm{HCl}$ with water and evaporated under nitrogen at $45 \mathrm{C}$. The methyl esters were made by adding two drops of methanol to the extract, then $0.5 \mathrm{ml}$ of an ethereal solution of diazomethane. This mixture was allowed to sit approximately one minute, and the excess ether and diazomethane were evaporated under nitrogen at $45 \mathrm{C}$. Then $\mathrm{CS}_{2}$ was added to the residue, and the methylesters were analyzed by gas-liquid chromatography (GLC).

\section{Chromatographic Analysis}

Gas chromatographic analysis of fatty acid methyl esters was performed with a gas 


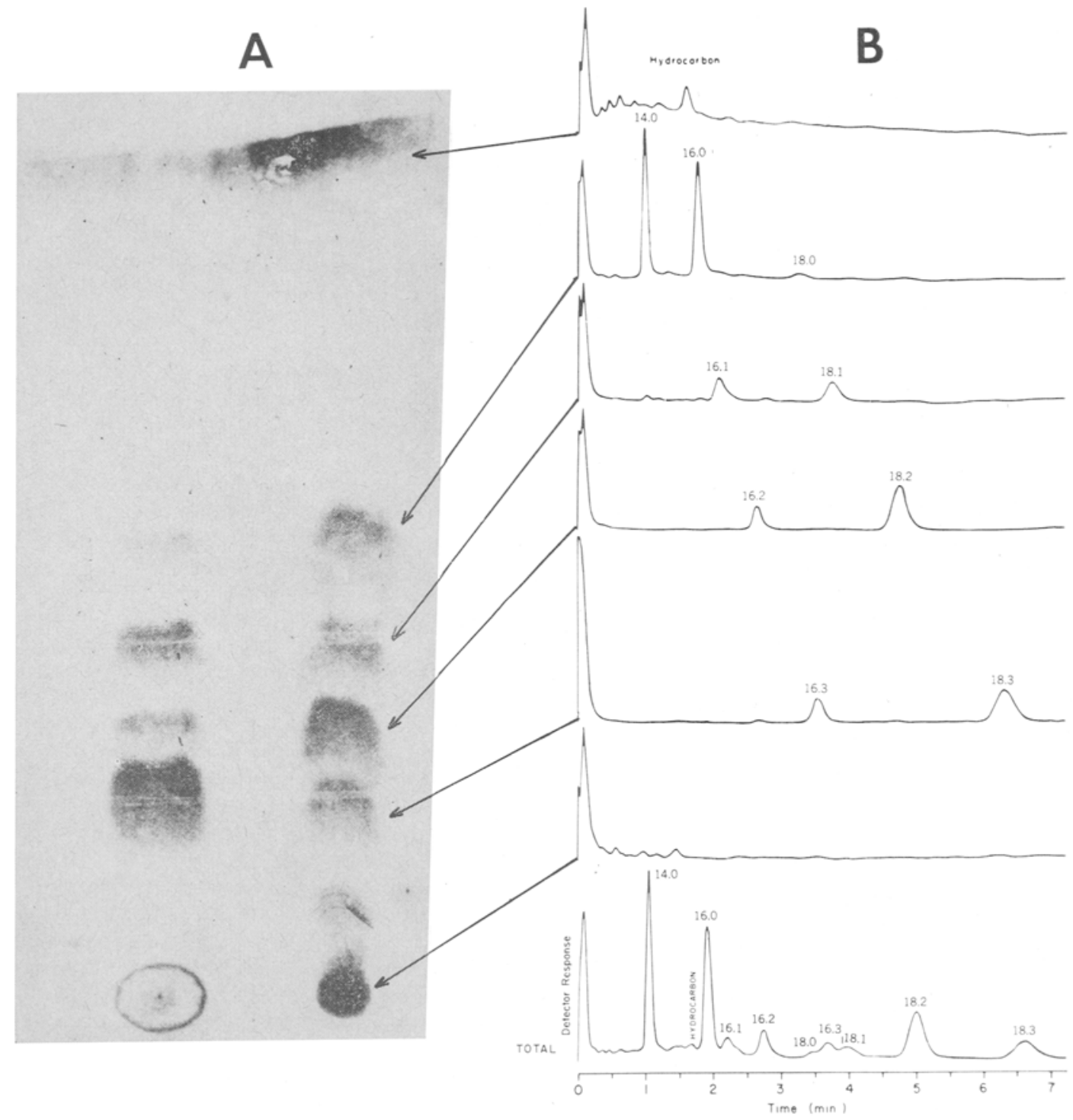

FIG. 1. The glass fiber paper chromatography (GFPC) and gas-liquid chromatography (GLC) identification of the fatty acid methyl esters of C. pyrenoidosa: A - A typical GFPC chromatogram, comparing the mobility of Chlorella fatty acid methyl esters (right) with that of a standard mixture (left). The standard mixture contains in order of decreasing mobility: methyl stearate, methyl oleate, methyl linoleate, methyl linolenate and arachidonate.

chromatograph (Packard Instrument Company), equipped with a hydrogen flame detector and a 6-ft. $\times$ 4-mm (I.D.) coiled glass column, which was packed with $10 \%$ EGSS$\mathrm{X}$ on 100/120 mesh Gas-Chrom P (Applied
B - Typical GLC chromatogram of algal fatty acid methyl esters eluted from a GFPC chromatogram. The bottom (total) is a GLC fatty acid pattern obtained from the total algal extract before separation of the fatty acids on GFPC. From left to right in the total GLC pattern appear methyl myristate (added as an internal standard), methyl palmitate, methyl palmitoleate, methyl hexadecadienoate, methyl stearate, methyl hexadecatrienoate, methyl oleate, methyl linoleate, and methyl linolenate.

Science Laboratories). The column was operated at $165-175 \mathrm{C}$ with a $\mathrm{N}_{2}$ pressure of 14 psi. The areas under the curves were measured by using a planimeter. Myristic acid, the internal standard, was used to calculate the con- 
centrations of the Chlorella fatty acids quantitatively.

\section{RESULTS}

\section{Extraction Efficiency}

An experiment was carried out to check the efficiency of extraction of the fatty acids. One complete cycle of sonication, saponification, $\mathrm{HCl}$ neutralization, and hexane extraction (see Methods) were all considered as one "extraction." On the basis of sequential "extractions," $98 \%$ of the total fatty acids were accounted for in the first "extraction." These extractions were performed on "steady-state" cultures to ensure extractability of the fatty acids from cells at all stages of growth. An amount of cell material, well in excess of the usual experimental sample-size, was used in these experiments to ensure complete extraction of the samples obtained during the synchronous growth experiments.

\section{Fatty Acid Identification}

Fig. 1 illustrates the procedure used to identify the fatty acids. The fatty acid methyl esters were spotted in a continuous line across the bottom of a silica gel-coated glass fiber paper. The glass fiber paper chromatogram (ITLC-SG, Gelman Instrument Company) was developed with iso-octane, and the fatty acid bands were located by spraying with Rhodamine 6G. Each band was cut from the chromatogram and eluted with chloroform. Fig. 1A shows the separation of the algal fatty acids compared with a known mixture. It can be seen that the saturated monoenoic, dienoic, and trienoic methyl esters separate from one another; however it should be noted that the tetraenoic methyl ester, arachidonate, did not separate from the trienoic methyl ester, linolenate. The components in the chromato- gram shown in Fig. 1A were detected by the $\mathrm{H}_{2} \mathrm{SO}_{4}$-char technique.

After the bands were eluted, they were subjected to GLC analysis. GLC tracings at the right of figure $1 \mathrm{~A}$ are joined to the section of the glass fiber paper chromatogram from which they were eluted. In the total algal fatty acid pattern at the bottom it can be seen that the algal fatty acids are a mixture of $\mathrm{C}_{16}$ and $\mathrm{C}_{18}$ acids. In each series there are saturated monoenoic, dienoic, and trienoic fatty acids.

Schlenk et al. (19) have identified six of the eight major fatty acids in a "steady-state" culture (a culture containing cells of all ages) of $C$. pyrenoidosa (No. 7516 American Type Culture Collection). Table I compares the fatty acid data of' Schlenk with that obtained from synchronous cultures of $C$. pyrenoidosa (7-11-05) at the zero and last hour of both experiments carried out in the present investigation. In the $C_{16}$ fatty acid series, palmitic acid was the dominant fatty acid in both investigations. In the $\mathrm{C}_{18}$ series Schlenk et al. found oleate to be a dominant acid followed by linoleate, linolenate, and stearate whereas this investigation with $C$. pyrenoidosa (7-11-05) showed that linoleate was the dominant fatty acid followed by linolenate, oleate, and finally stearate.

It is interesting to note from the data in Table I that, regardless of small changes in percentage composition, the relative order of the composition in terms of concentration (i.e., $16: 0>16: 2>16: 3>16: 1 / 18: 2>$ $18: 3>18: 1>18: 0$ ) was almost unaffected by the growth conditions to which the cells were exposed throughout one complete growth cycle. Whether these patterns are altered during successive generations of growth under identical growth conditions or whether they are characteristic for $C$. pyrenoidosa 7-11-05 will be studied in future investigation.

TABLE I

A Comparison of the Fatty Acid

(Strain No. 7516 and No. 7-11-05) Composition of C. pyrenoidosa

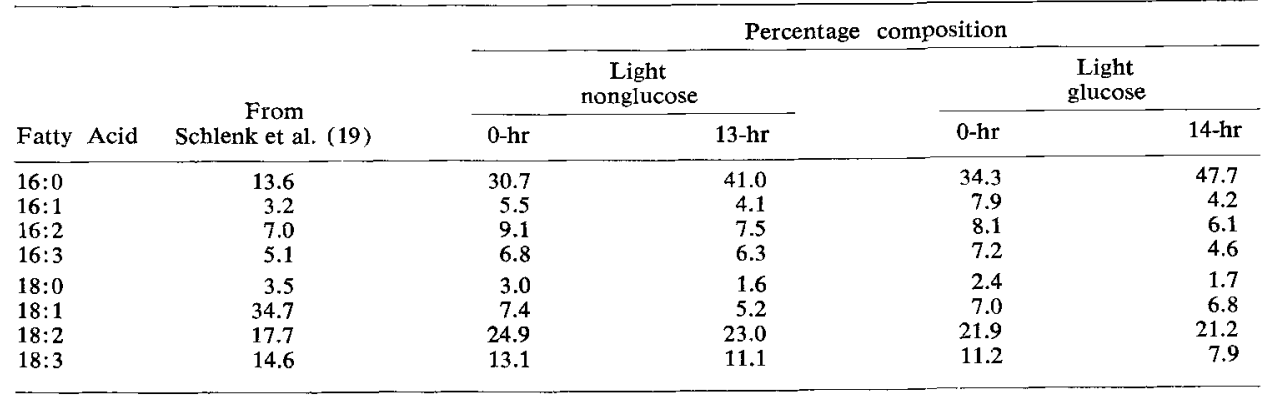

LIPIDS, VoL. 2, No. 5 
Fig. 2 illustrates the synchronized cell division that was observed in "light-grown" cells in the presence and absence of glucose. In the absence of glucose the synchronized cell division was similar to that obtained in other laboratories with $C$. pyrenoidosa (6-8). In cultures grown with glucose, daughter-cell release was delayed by approximately two hours, and, in some cells, division was inhibited completely (as indicated by the fact that there was only approximately a three-fold increase in cell number). Microscopic examination of the culture during division revealed that there were many cells larger than the normal mother cells and that cytokinesis, when it occurred, resulted in the release of four daughter cells. Each "giant" mother cell was similar in appearance to those photomicrographed by Rodriguez-Lopez (20).

The log-linear increase in total cellular dry weight and phosphorus of cultures grown in the light in the absence of glucose (Fig. 3), has been established on numerous occasions $(6,7,16)$. The dry weight (Fig. 3A) of cells exposed to glucose at two hours was equal to the dry weight of cells not exposed to glucose at three hours, indicating a faster rate of growth for the former. After four hours the rate of dry-weight increase in cells exposed to glucose dropped off and remained log-linear throughout the remainder of their growth cycle. The rate of increase was less than that observed for cells not exposed to glucose. These latter data were consistent with numerous reports (21) of the failure of exogenous energy sources to stimulate growth under conditions which are saturating for photosynthesis. The accelerated dry-weight increase during the initial four hours of growth was consistent with the hypothesis that glucose is directly utilized in starch biosynthesis (11). The rate of total cellular phosphorus increase of cells exposed to glucose (Fig. 3B), which probably would not reflect an enhanced starch biosynthesis, increased log-linearly through the eighth hour; thereafter the rate decreased (remaining $\log$ linear) throughout the period where cell division was inhibited.

A two-hour lag in the accumulation of the total fatty acids was observed and was followed by a nearly uniform increase through the sixth hour in photo-autotrophically grown cells (Fig. 4A). Between the sixth and seventh hours [about one hour before the onset of nuclear division (9)], the rate of increase of total fatty acids was appreciably depressed. Throughout nuclear division and cell division

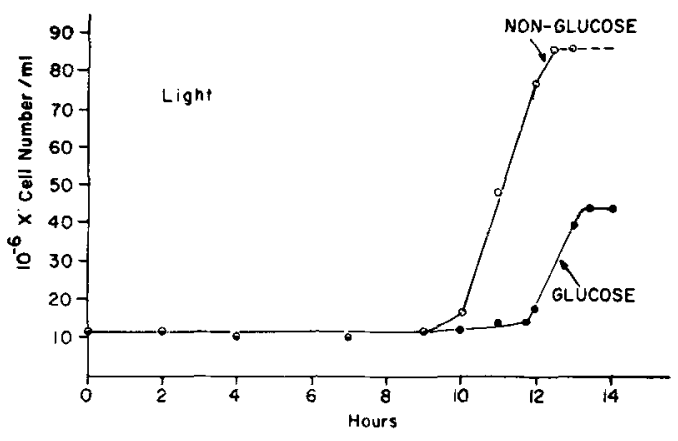

Fig. 2. A comparison of the cell concentration of C. pyrenoidosa during synchronous growth in the light in the presence and absence of glucose.

(seventh through 12.5 hour) the total fatty acid content of the cells increased uniformly. In the photoheterotrophically grown culture (Fig. 4B) there was a linear accumulation in total fatty acids until the fourth hour, at which time there was an abrupt increase until the sixth hour. Between the sixth and seventh hours of growth there was a marked decline in fatty acid accumulation, which was more pronounced than the decline observed in the absence of glucose during the same interval. An accelerated accumulation of total fatty acids was again observed during nuclear di-
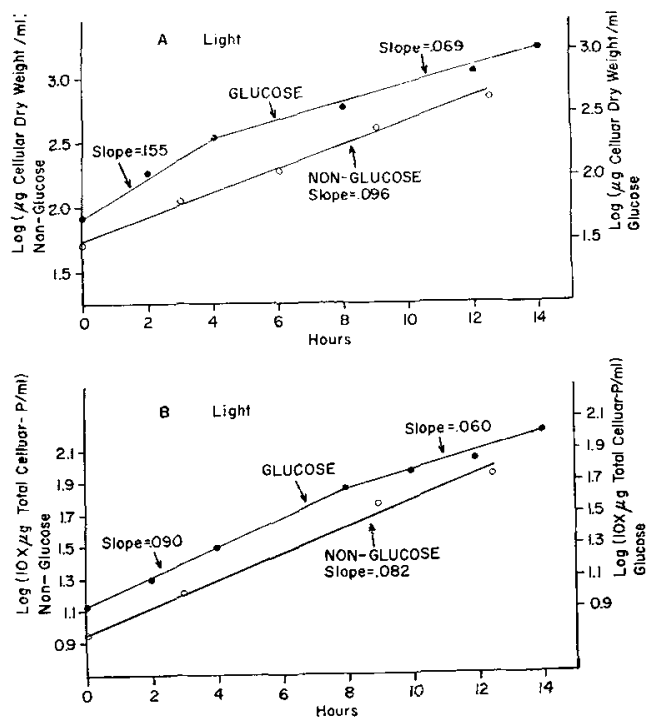

FIG. 3. A comparison of the increase in the total dry weight (A) and total cellular phosphorus (B) of synchronized cultures of $C$. pyrenoidosa grown in the light in the presence and absence of glucose. 

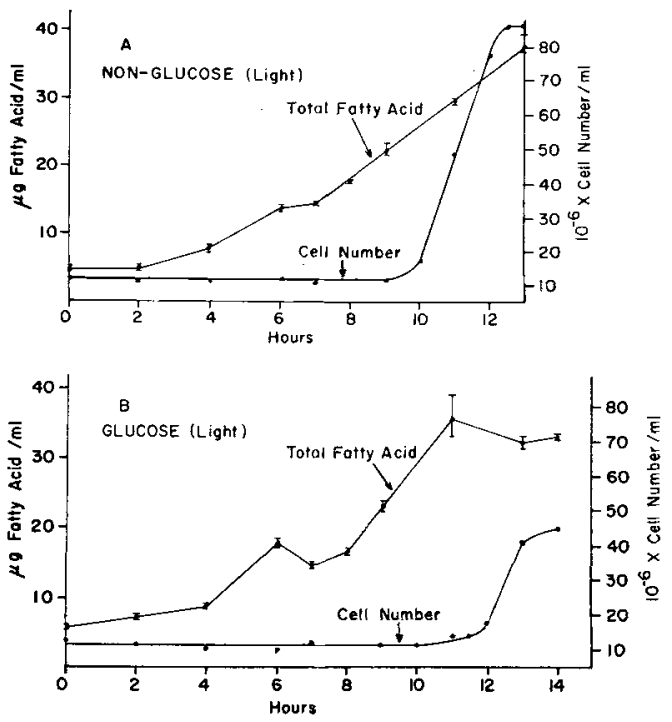

FIG. 4. Relationship between the total cellular fatty acids and cell concentration of synchronized cultures of $C$. pyrenoidosa grown in the light in the presence (B) or absence (A) of glucose.

vision, but, in contrast to the photo-autotrophically grown culture, the fatty acid accumulation ceased during cell division. The decrease in the rate of fatty acid accumulation during cell division of the cells exposed to glucose was not reflected in their dry-weight increase, which was log-linear from the fourth hour of growth (Fig. 3A). Thus, during growth of cells exposed to both light and glucose, the fatty acid concentration, rather than dry weight, seems more clearly to reflect the observed inhibition in cell division. Even though there were differences in accumulation curves, whether the cells were grown in the presence or absence of glucose, the total fatty acid content of the cultures after one growth cycle was nearly the same.

For the most part the changes in the individual fatty acids (Fig. 5) reffected the over-all trends in total fatty acid content (Fig. 4). There were several exceptions. In the photo-autotrophically grown cells only hexadecatrienoate and linolenate increased measurably during the first two hours of growth. After the first two hours palmitate increased at a log-linear rate, showing no decline during the sixth-seventh hour. Only palmitate and linoleate increased appreciably during cell division; the concentration of all other fatty acids remained essentially constant during the period. The concentration of each fatty acid, except palmitate, seemed to have a depressed rate of accumulation during the prenuclear division period. Linolenate showed the most marked depression.

The presence of glucose did not alter the similarities between the individual fatty acids (Fig. 5B) and the total fatty acid content (Fig. 4B). Most of the fatty acids increased during the first two hours of growth; the greatest increase was again observed in linolenate. In contrast to the photo-autotrophically grown cells nearly all fatty acids, including palmitate, declined markedly in concentration during the prenuclear division period. Each fatty acid increased during nuclear division and declined during cell division except for palmitate, which continued to increase during the latter stage of growth. Linoleate concentration increased considerably during cell division in photoautotrophically grown cells; but in photoheterotrophically grown cultures the linoleate concentration dropped markedly during the cell division period.

\section{DISCUSSION}

Periodism in cytological (5) (such as nuclear and chloroplast division, cross-wall deposition, etc.) as well as metabolic $(9,10)$ events (photosynthetic activity and endogenous respiration) during the maturation cycle of Chlorella would seem to require an accompanying periodism in biochemical components related to these events. This hypothesis has received support on numerous occasions $(3,6,7,16,17)$ in synchronized cultures of $C$. pyrenoidosa.

The dramatic cytological changes in this organism, most of which occur in a two to three-hour period just before and during daughter-cell release, would seem to indicate that this period is one in which the energygenerating systems of the cell are operating at their maximum. Sorokin however has repeatedly demonstrated $(8,10)$ that photosynthetic activity, which has been steadily declining since the fifth hour of growth, is approaching its lowest level during cell division. Since the major energy source of the organism operates minimally during this period, Duynstee (11) has postulated that, in order to meet its demands for energy- and/or carbonbuilding blocks, the cells must mobilize the carbohydrate and/or lipid reserves which have accumulated prior to this point. The decrease Duynstee observed (11) in the rate of total starch accumulation from the sixth hour of growth is consistent with its utilization as a

LIPIDS, VoL. 2, No. 5 

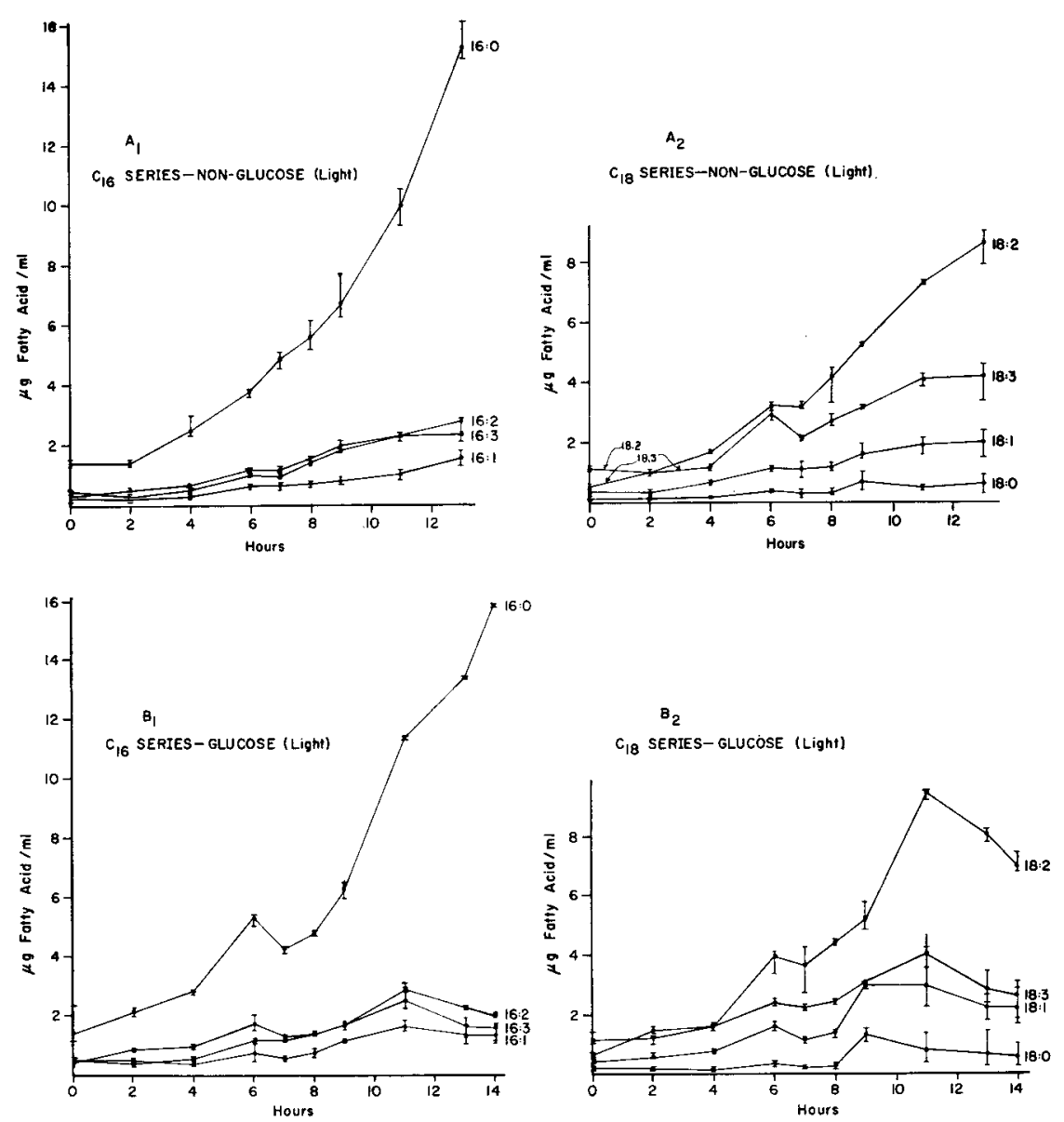

FIG. 5. A comparison of the individual fatty acid concentrations of synchronized cultures of C. pyrenoidosa grown in the light in the presence $\left(B_{1} B_{2}\right)$ and absence $\left(A_{1} A_{2}\right)$ of glucose.

carbon and/or energy reserve from the sixth hour of growth through cell division.

The role of the fatty acids as a possible contributor to the cell economy is not so clear. The rate of increase in the total cellular concentration of most of the fatty acids was depressed (sixth-seventh hour) just prior to nuclear (9) and chloroplast (5) division (seventh-tenth hour) and during cellular division (Fig. 5A). Linolenic acid was the only fatty acid to show an unequivocal net utilization during the prenuclear division period, suggesting perhaps more than a structural role for this lipid during this period. Palmitic acid, the dominant fatty acid in this organism, does not show a periodism during either the prenuclear or cell division periods but rather accumulates at an exponential rate (these data have been plotted but do not warrant an additional figure) from the second hour of growth throughout the life cycle. Since accumulation data are a net result of both synthesis and catabolism, it can only be concluded that the rate of palmitic acid synthesis always exceeds its rate of breakdown and that, since the accumulation is exponential, its rate of synthesis increases at least at the same exponential rate. By using ${ }^{14} \mathrm{C}$ labeling techniques it is hoped that future experiments will be able to assess the turn-over rate of these fatty acids.

In an attempt to elucidate the relative contributions of the fatty acids to an intracellular carbon energy pool, a second experiment was performed, in which glucose was supplied as an exogenous carbon and energy source to synchronously growing Chlorella cultures.

This experiment provided several interesting results. The lag in fatty acid accumulation 
observed during the first two hours of growth in photo-autotrophically grown cultures was absent when the cells were grown in the presence of glucose (Fig. 4). Presumably this is a result of the fact that glucose supplies more direct precursors of fatty acid biosynthesis than do photosynthetic products. If such is the case, one would expect starch (17$20 \%$ of the cellular dry weight) rather than lipid content (3-4\% of the cellular dry weight) more nearly to reflect a cellular demand for energy since the product of starch catabolism, glucose, should promote lipid biosynthesis rather than lipid catabolism. The net utilization of nearly every fatty acid during both the prenuclear and cell division stages of growth in cultures exposed to glucose (Fig. $5 \mathbf{B}_{1}+\mathbf{B}_{2}$ ) is however inconsistent with this suggestion. Rather than promoting fatty acid biosynthesis or at least lessening the rate of decline in fatty acid content, glucose administration promotes a net utilization of the fatty acids. The possibility that intracellular glucose plays a regulatory role in the utilization of intracellular fatty acids is an intriguing but speculative hypothesis from these data.

The observed inhibition of daughter-cell release observed in photoheterotrophically grown cultures, not unique to this laboratory (20), remains unexplained. The heterotrophic growth of Chlorella is currently under investigation in this laboratory.

The relationship of fatty acids, specifically $\alpha$-linolenic acid and trans-3-hexadecenoic acid, to the Hill reaction in green plants and micro-organisms has been studied in several laboratories $(2,12,13,14)$. The absence of these fatty acids from two species of bluegreen algae which was nevertheless capable of carrying out the Hill reaction led Nichols (14) to conclude that the essential participation of either $\alpha$-linolenic or trans-3-hexadecenoic acid in the Hill reaction can be discounted. Yet the lack of a universal distribution of these acids does not automatically preclude a unique association of these fatty acids with photosynthesis in the green algae or higher plants.

Sorokin (10) has reported that the photosynthetic activity in synchronized cultures of C. pyrenoidosa rises sharply during the first four hours of growth, peaks at this time, then progressively declines throughout the remainder of the life cycle. Though linolenate was the only fatty acid to show a measurable increase during the first two hours of photoautotrophically grown cultures, its rate of ac- cumulation is increased between the 4th and sixth hours of growth. After a brief prenuclear division drop in concentration, linolenate concentration then increases throughout the remainder of the life cycle. Thus linolenate, if related to the photosynthetic process at all, certainly has additional role(s) to play during cell development. It must be pointed out however that it is possible that only small amounts of the total linolenate in the cell are required for the photosynthetic function and that, once this requirement is met (i.e., during the initial period of growth), additional linolenate takes part in other cellular processes. The trans-3hexadecenoic acid content of this organism, presumably represented by the shoulder on the $16: 1$ peak in the total algal fatty acids shown in Fig. $1 \mathrm{~A}$, represents such a small fraction of the total fatty acids in this organism (since it was always included in the estimate of $16: 1$ ) that its periodism during the growth cycle could not be reliably estimated from these data. It is unfortunate that the conditions necessary to rupture the organism will not permit subsequent isolation and chemical analysis of its organelles.

Results on the fatty acid pattern of Chlorella agree well with those of Schlenk (19) et al. with the exception of oleic acid. Aside from a possible strain difference between organisms, oleic acid content has been reported (22) to be drastically reduced in growth media similar to the authors', which have a high nitrogen content.

The role(s) which fatty acids play during cell maturation of this organism remain elusive. Observations (in triplicate) of the eight principal fatty acids under two different growth conditions do however seem to indicate their likely involvement in processes which occur during both the prenuclear and cell division stages of growth in $C$. pyrenoidosa.

\section{ACKNOWLEDGMENT}

This work was supported in part by the Cancer Association of Greater New Orleans Inc. Grant No. 911-65, and TIGM-0648-05 USPHS.

\section{REFERENCES}

1. Miller, J. D. A., "Physiology and Biochemistry of the Algae," Academic Press Inc., New York, N. Y., 1962, p. $357-370$.

2. Nichols, B. W., Biochem. Biophys. Acta 106, 274-279 (1965).

3. Schmidt, R. R., "Cell Synchrony," Academic Press Inc., New York, N. Y., 1966, p. 189-235.

4. Maaloe, O., "The Bacteria," Vol. IV, Academic Press Inc., New York, N. Y., 1962, p. 1-32. 
5. Marakami, S., Y. Morimura and A. Takamiya, "Studies on Micro-algae and Photosynthetic Bacteria," The University of Tokyo Press, 1963, p. 65.

6. Schmidt, R. R., and K. W. King, Biochem. Biophys. Acta 47, 391-392 (1961).

7. Schmidt, R. R., Ph.D. Dissertation, Virginia Polytechnic Institute, Blacksburg, Va., 1961.

8. Sorokin, C., Biochem. Biophys. Acta 94, 42-46 (1965).

9. Curnutt, S. G., and R. R. Schmidt, Exptl. Cell. Res. 36, 102-110 (1964).

10. Sorokin, C., Physiol. Plant. 10, 659-666 (1957).

11. Duynstee, E., and R. R. Schmidt, Arch. Biochem. Biophys., 119, 382-386 (1967).

12. Erwin, J., and K. Bloch, Biochem. J, 338, 496-511 (1963)

13. Nichols, B. W., B. J. B. Wood and A. T. James, Biochem. J. 95, 6P (1965).
14. Nichols, B. W., R. V. Harris and A. T. James, Biochem. Biophys. Res. Comm. 20, 256-262 (1965).

15. Sorokin, C., and J. Myers, Science 117, 330 (1953).

16. Johnson, R. A., and R. R. Schmidt, Biochem. Biophys. Acta 74, 428-437 (1963).

17. Schmidt, R. R., Exptl. Cell. Res. 23, 203-208 (1961).

18. Fiske, C. H., and Y. Subbarow, J. Biol. Chem. 66 , 375-381 (1925).

19. Schlenk, H., H. K. Mangold, J. L. Gellerman, W. E. Link, R. A. Morrissette, R. T. Holman and H. Hayes, JAOCS 37, 547-552 (1960).

20. Rodriguez-Lopez, Nature 199, 506-508 (1963).

21. Fogg, G. E., "The Metabolism of Algae," John Wiley and Sons Inc., New York, N. Y., 1953.

22. Paschke, R. F., and D. H. Wheeler, JAOCS 31, 81-85 (1954).

[Received March 13, 1967] 